\title{
РЕВОЛЮЦИИ
}

А.В. Рыбалова

DOI: 10.7256/2305-560X.2014.3.11785

\section{РЕВОЛЮЦИЯ В СИРИИ КАК ОБНОВЛЕННАЯ СХЕМА РЕАЛИЗАЦИИ ЦВЕТНЫХ РЕВОЛЮЦИЙ}

\begin{abstract}
Аннотация: События последних лет в политике и международных отношениях показывают важную роль нового механизма реализации государственного переворота ненасильственным способом - механизма иветных революций. Особенно интересной в данном контексте является весьма острая и актуальная тема конфликт в Сирии, который длится с 2011 года по настоящее время. Актуальность исследования обеспечена относительной новизной феномена цветных революций, а также его активного использования в современном мире в интересах организации государственных переворотов ненасильственным путем. Сирийский конфликт заключается в массовых выступлениях и протестах, имеющих антиправительственный характер, который начался в Дераа 15 марта 2011 года. Первое выступление демонстрантов породило серию новых выступлений и вылилось в массовое восстание сирийского народа. Проблематика иветных революций наиболее актуализирована сейчас из-за глобальности ее распространения в странах Ближнего Востока и Северной Африки. Принимая во внимание актуальность данной темы, настоящая работа посвящена проблеме реализации и внедрения механизмов осуществления государственных переворотов, известных под общим названием англосаксонских цветных революций, в Сирии.
\end{abstract}

Ключевые слова: международные отношения, внешняя политика, арабские револючии, геополитика, политическая нестабильность, дипломатия, государство, Сирия, цветные революции, Ливия.

\section{История сирийского конфликта}

Причинами данного конфликта считаются недовольство политическим курсом страны, коррумпированность власти, а также этно-религиозные разногласия и противоречия. Поводом начала активных действий послужило создание группы в социальной сети Facebook «Сирийская революция-2011», в которой были призывы к осуществлению переворота власти в государстве, на который откликнулись несколько сотен человек. Требования были стандартными для требований любой рассмотренной ранее цветной революции: демократия, свобода слова, устранение диктатуры и отставка президента Башара Асада, прекращение правления партии Баас (ПАСВ - Партия арабского социалистического возрождения).

После ряда выступлений, включающих голодовки, демонстрации, митинги, правительство пошло на некоторые уступки: был сменен премьерминистр, правительство отправлено в отставку, а также отменен режим чрезвычайного положения в стране (был введен в стране 50 лет назад). Однако это не удовлетворило повстанцев, и недовольства продолжились. В декабре 2011 года произошел крупный теракт в Дамаске, после которого Башар
Асад пообещал положить революционным настроениям конец. Однако шествия и недовольства продолжались. Правительство, в свою очередь, для их подавления использовало танки и артиллерию. В ответ повстанцы развернули полномасштабную атаку и начали формировать отряды для того, чтобы найти и свергнуть президента страны.

В апреле 2012 года на время было объявлено перемирие, однако столкновения в стране продолжались. 8 мая прошли выборы в Народный Совет, в ходе которых победу одержал блок, созданный партией Баас. С мая отмечается активное вмешательство иностранных государств во внутренние проблемы страны. С тех пор как в Сирии, так и за рубежом начали признавать, что идет гражданская война.

Гражданская война в Сирии отмечена привлечением исламистов и многочисленными террористическими актами в различных городах.

31 марта 2012 года Дамаск заявил, что гражданская война и революция в Сирии закончилась, а оппозиция оставила идею свержения правительства ${ }^{1}$. «Б.Асад ранее заявил, что принимает план мирного урегулирования, предложенный международным

$1 \quad$ http://top.rbc.ru/politics/31/03/2012/644271.shtml 
посланником Кофи Аннаном, а именно: прекращение насилия всеми сторонами конфликта, выведение войск из городов, оказание гуманитарной помощи пострадавшим, начало политического диалога, исключение вмешательства в ситуацию извне и создание эффективного механизма мониторинга за выполнением этих требований».

Однако несмотря на данные заявления, боевые действия продолжились и ведутся до сих пор. Более того, в июне 2012 года официальный представитель военного совета сирийских повстанцев майор Сами аль-Курди заявил об отказе соблюдения перемирия с правительственными силами. 13 июня глава Департамента операций по поддержанию мира ООН Эрве Ладсус официально назвал конфликт в Сирии гражданской войной и заявил, что правительство потеряло контроль над многими городами и населенными пунктами². Более того, повстанцы отказались выполнять план Кофи Аннана, что стало причиной думать, что предпосылок для мирного урегулирования конфликта нет.

Если официальной причиной начала войны в Сирии называли борьбу за демократию и права человека, то в то, что сейчас идет война за демократические ценности, не верит никто. Запад настаивает на развитии ливийского сценария, в то время как Россия и Китай выступают за мирное решение конфликта; исламские фундаменталисты никого не слушают и продолжают свой джихад, а правительство Сирии просит мировое сообщество дать ему возможность решить свою судьбу самостоятельно.

С 2013 года данная ситуация в Сирии ухудшилась. Так, 21 августа стало известно о применении химического оружия в виде нервно-паралитического газа зарин в районе Гута вблизи Дамаска, что привело к жертвам. По различным данным, погибло от 300 до 1600 человек.

В середине сентября прошлого года Россия и США согласовали порядок вывоза химоружия из Сирии и его уничтожения. Вскоре была создана совместная миссия $00 \mathrm{H}$ и 03ХО, которая отвечает за реализацию плана. По утвержденному графику, приоритетные химвещества, включающие около 20 тонн токсичного горчичного газа, должны быть вывезены до 31 марта 2014 года, а к концу июня 2014 года сирийское химоружие должно быть полностью уничтожено.

\footnotetext{
2 И.Яковин. Уровнем выше. - 2012. http://lenta.ru/ articles/2012/06/14/newturn/
}

Нужно отметить, что сегодня в Сирии столкновения не ограничиваются противостоянием вооруженных отрядов повстанцев и правительственных сил. Сейчас на территории страны разворачивается война между «Исламским государством Ирака и Леванта» и «Джабхат ан-Нусра» с «Аль-Каидой».

\section{Признаки цветной революции в сирийском конфликте}

Одним из главных споров политических исследователей помимо вопроса об итогах и конце военных действий в Сирии является спор о том, является ли конфликт звеном в цепочке цветных революций арабской весны или же это отдельный «проект», не подпадающий под определение классических цветных революций.

Как было выделено в предыдущей работе, все цветные революции имеют общие черты и особенности вне зависимости от времени, места и сценария их протекания. К ним можно отнести:

- демократический или полудемократический характер революционных государств

- $\quad$ открытость в организации и проведении цветной революции

- революционные действия имеют ненасильственный характер

- $\quad$ революционные действия часто начинаются в период после выборов, когда оппозиция объявляет об их фальсификации

- $\quad$ молодежь как опора и главная действующая сила.

- $\quad$ в главе оппозиции находятся люди, ранее входившие в состав властных структур, так называемая контрэлита, отстраненная от власти

- молниеносный характер действий

- значительная роль внешних сил

- использование символики.

Что касается схем осуществления цветных революций, то можно условно обозначить два сценария:

1) Ранние цветные революции в странах Восточной Европы (например, Чехословакия, Грузия, Украина, Киргизия).

Их отличает особый сценарий. Во-первых, в большинстве своем события таких цветных революций развиваются на фоне предвыборной кампании или непосредственно самих выборов. После подсчета голосов оппозиция заявляет о фальсификациях со стороны набравшего большее количество голосов и объявляет о своей победе.

2) Цветные революции «арабской весны» (например, Тунис, Египет, Ливан и др.). Данные революции отличает то, что их причиной, как правило, 
становится объявление существующего режима диктаторским и нелегитимным.

Анализируя события в Сирии, можно проследить несколько закономерностей. Во-первых, время возникновения конфликта. Как известно, с самосожжения Мухаммеда Буазизи в Тунисе в декабре 2010 года началась арабская весна. Затем предоставляется возможным проследить цепочку стран, в которых развивались революционные действия. Тунис-Египет-Ливия-Сирия-Бахрейн-Йемен. Выбор этих стран обусловлен различными политическими, экономическими, стратегическими и географическими факторами. Тот факт, что приблизительно в одно время в одном регионе началась волна похожих друг на друга демонстраций и военных действий с одинаковыми требованиями и лозунгами, дает основания предполагать, что появление Сирии в этом ряду не случайно.

Во-вторых, одной из движущих сил действительно является молодежь, которая, как и в предыдущих цветных революциях, поднялась с требованием свободы. Помимо отсутствия опыта и жизненных ориентиров, молодые люди меньше остальных категорий населения подвержены влиянию идеологии и стремлением оказаться у власти. Так, в большинстве своем молодежь не имеет четкого представления о понятии свободы в современном мире, однако воспевает ее как новый идеал и видит себя главной силой при построении новой Сирии.

Одним из отличий сирийской революции является то, что действующей силой была не только молодежь, но и интеллигенция, в том числе и женская.

В-третьих, начало конфликта было «классическим» для цветных революций. Так, во всех революциях в Северной Африке и на Ближнем Востоке было отмечено отсутствие идеологического базиса революции. Так же происходило в Сирии: отсутствие идеологии, прикрытое лозунгами о демократических правах и свободах, а также требование свержения правящего режима.

Также нужно отметить, что, как любая другая революция арабской весны, революция в Сирии характеризуется открытостью организации и имеет значительную роль внешних сил.

Однако с другой стороны, характер происходящих в Сирии событий сложно назвать молниеносным.

Проводя анализ осуществленных цветных революций, можно сделать вывод о том, что часть признаков конфликта в Сирии четко можно назвать классифицировать как признаки цветной революции, а часть нет. Однако отсутствие каких-либо компонентов не является показателем того, что это не цветная революция, более того, это может служить доказательством того, что схема реализации цветных революций претерпевает изменения.

Как показывает практика, схема реализации цветных революций постоянно дополняется и дорабатывается. Так, в событиях арабской весны наблюдается еще один ключевой элемент - механизм обратной связи, обязательно присутствующий в любой специальной операции. Он заключается в том, что схема, разработанная для реализации цветной революции в одной стране изменяется и подвергается корректировке после ее «обкатки» перед использованием в другой стране. Принцип обратной связи позволяет выявлять и исправлять ошибки, оперативно адаптировать его под тонкую специфику региона, которая проявляется, как правило, уже в процессе реализации исходного замысла. В этом - гибкость современных технологий «цветных революций» и, одновременно, их главный демаскирующий признак.

Именно поэтому можно сделать предположение о том, что несмотря на весомые различия и несоответствия классической схеме, военные события в Сирии можно отнести к событиям цветной революции.

\section{Причины затяжного характера революционных событий в Сирии}

Имея признаки цветной революции, конфликт в Сирии, по мнению большинства политологов и экспертов, должен был, как и любая другая цветная революция, быстро завершиться. Однако сирийский режим, несмотря ни на что, держится уже около трех лет, он оказался самым «живучим»в арабском регионе, а режим Асада не пал и, более того, борется за власть, не считаясь с потерями. В результате военный конфликт перерос в гражданскую войну ${ }^{3}$.

Среди причин, объясняющих «стойкость» политического режима Башара Асада, можно выделить:

1) Международную поддержку. В частности, помощь и защита со стороны России и Китая, которые используют право вето при обсуждении революционных резолюций в СБ ООН.

\footnotetext{
3 Манойло А.В. «Сирийский вопрос» Башара Асада. "NB:
} Международные отношения". - 2013, - №2, с.48-67. 
2) Готовность президента Башара Асада. Цветная революция в Ливии и судьба Муаммара Каддафи наглядно показали, как могут развиваться события в охваченной повстанцами и интервентами стране и каким может быть итог.

3) Поддержку внутри государства. Во-первых, часть населения выступает за режим Асада изза боязни что-то потерять. Во-вторых, остальная часть (около трети населения страны) боится изменений к худшему в случае победы суннитов. Более того, согласно данным, около $40 \%$ населения Сирийской Арабской Республики просто не видят альтернативы Асаду, который рассматривает как гарант независимости и защиты от радикалов ${ }^{4}$.

4) Соотношение сил. Военное превосходство имеют правительство и его сторонники. Так, сухопутные силы армии Сирийской Арабской республики составляют 220 тысяч человек, военно-воздушные-40 тысяч человек, военно-морские-7,6 тысяч человек ${ }^{5}$. Также несмотря на проблемы, связанные с вооружением, Сирийская армия за последнее время сумела существенно повысить его техническое состояние. В свою очередь противостоящая ей Свободная Сирийская армия (ССА) состоит по различным оценкам от 30 до 50 тысяч человек 6 . По заявлениям самой группировки на июнь 2013 года она насчитывала 80 тысяч боевиков ${ }^{7}$. Одновременно с этим один из главных «поставщиков» оппозиции Турция сейчас находится в состоянии внутриполитической нестабильности, а в Катаре, поддерживавшем до недавнего времени сирийских повстанцев, к власти пришел новый эмир Тамим бин-Хамад, для которого сирийский конфликт не является первоочередным.

5) Неспособность революционно настроенных групп полностью контролировать хотя бы один регион, а также частичная утрата контро-

4 Владимир Евсеев. Сирийская развязка. «Независимое военное обозрение». - 2013, 20 сент.

5 А. Сидорин, Г. Мингатин, В. Прищепов, В. Акуленко. Вооруженные силы зарубежных государств. 2009.

6 Сирийская свободная армия заявляет о контроле над сторонниками шариата. - 2013, 1 окт. http://ria.ru/arab_ riot/20131001/966948194.html

7 Freedom fighters? Cannibals? The truth about Syria's rebels. 2013, 17 июня. http://www.independent.co.uk/news/world/ middle-east/freedom-fighters-cannibals-the-truth-about-syriasrebels-8662618.html ля правительством над некоторыми городами. По заявлению министра обороны Израиля Моше Яалона, «Сирия расколота на две части. Президент Башар Асад контролирует 40\% территории страны. В Дамаске как минимум четыре района города находятся в руках повстанцев. Ситуация в Сирии непредсказуема» ${ }^{8}$. Так, вооруженная оппозиция удерживает значительную часть провинций Идлиб, Халеб и Дейр аз-Зор, а также часть города Алеппо и его окрестностей, районов турецкой и иорданской границ ${ }^{9}$.

6) Внимание США переместилось с Сирии на Украину, а поставки боевого и небоевого оружия снизились. Однако это не означает полного отказа от проводимой политики в Сирии, потому что, по мнению вице-президента Академии геополитических проблем К.Сивкова, «отступиться от Сирии - как, кстати, и от Украины, - для политической элиты США совершенно неприемлемо. Если они отступятся от Сирии, то влияние их на Ближнем Востоке резко снизится». Это может служить основанием считать, что конфликт в Сирии не близится к своему завершению, а лишь переходит в новую, более спокойную фазу.

\section{Сирия и Ливия: общее и различия}

Многие исследователи и эксперты отмечают, что военные действия, которые происходили на территории Сирии, напоминали «ливийский сценарий».

В ноябре 2011 года на вопрос о возможности повторения ливийского сценария президент Института изучения Ближнего Востока и Израиля Евгений Сатановский ответил так: «Я не просто его не исключаю, я убежден, что к этому все готово».

Среди общих черт между революциями

А.В.Манойло отмечает:

- организацию протестного движения внутри страны, которое напоминает массовую кампанию вербовки наемников;

- $\quad$ выдвижение на роль новых лидеров государства малоизвестных деятелей из числа эмигрантов (таких как кабинетный ученый Гальюн, постоянно проживающий в Париже), единственной ценностью которых является

\footnotetext{
8 http://newsland.com/news/detail/id/1188769/

9 Владимир Евсеев. Сирийская развязка. «Независимое военное обозрение». - 2013, 20 сент.
} 


\section{Международные отношения / International Relations}

полная управляемость и преданность своим западным кураторам;

- $\quad$ создание всевозможных «теневых кабинетов министров» и псевдонародных «фронтов», таких как «Патриотическая коалиция в поддержку демократических перемен», «Национальный Совет Сирии», которые позиционируют себя как истинные представители народа и руководящие органы многочисленной внутренней оппозиции, недовольной режимом Б. Асада ${ }^{10}$.

Однако несмотря на всю схожесть, практически все сходятся в том, что «ливийский сценарий» в Сирии не дойдет до своего логического завершения. Как отмечал Е.Сатановский, «применение силы внешними странами, как это было в Ливии, не пройдет незамеченным, так как с этим не согласятся Россия и Китай» ${ }^{11}$. На практике все так и произошло. Если в 2011 году Барак Обама принял решение о бомбардировке Ливии без поддержки Конгресса (статья I раздел 8 Конституции США), пояснив, что конфликт в Ливии не является войной, а лишь небольшим военным ударом, который продлился не больше двух месяцев, то два года спустя его попытка заручиться поддержкой Совета Безопасности ООН для начала войны в Сирии не увенчалась успехом, так как Москва и Пекин отвергли проект резолюции. Более того, все меньше стран одобряют идею вторжения или нападения на Сирию по сравнению с ситуацией в Ливии. Таким образом, вектор событий был направлен в сторону политического урегулирования ситуации и начала химического разоружения.

Однако, как видно из текущей ситуации в Сирии, это еще не окончательная победа, и многое предстоит сделать для урегулирования сирийского вопроса.

Сравнение Сирии с Ливией напрашивается отчасти потому, что ливийская армия успешно боролась с оппозицией. Когда стало ясно, что оппозиция не справится сама, тогда возникла резолюция ООН, которая была по-своему сынтерпретирована. По сути наносились удары, погибло много гражданского населения. Очень похожее наблюдается и в Сирии.

Председатель комитета Госдумы по международным делам Алексей Пушков видит отличие резолюции Совета Безопасности ООН по сирийскому

\footnotetext{
10 Манойло А.В. Цветная революция в Сирии: возможные причины и промежуточные итоги. Мир и политика. - 2012.

11 http://ria.ru/arab_sy/20111114/488477195.html
}

оружию от принятого в свое время решения Совбеза по Ливии в том, что она не предусматривает применение силы. «Резолюция СБ по Сирии не дает санкции на применение силы и этим кардинально отличается от резолюции по Ливии. Поэтому ее приняли единогласно» ${ }^{12}$.

Как уже отмечалось, Сирия и Ливия находятся в одном регионе. Однако роль, которую они играют на Ближнем Востоке различна. Так, Ливия имеет менее важное стратегическое значение. В отличие от нее Сирия играет центральную роль на Ближнем Востоке.

На этом различия не заканчиваются. Вопервых, нельзя сравнивать военную мощь Ливии и Сирии. Ливийская армия еще до начала военных действий была в полуразваленном состоянии, Каддафи доверял не своим военным, а утопической концепции «вооруженного народа». Так, с 31 августа 1988 года Муаммар Каддафи объявил о роспуске армии и полиции и одновременно о создании объединений сил «вооруженного народа». Согласно данной идее силы вооруженного народа без привлечения аппарата службы безопасности и охраны должны были быть способными отразить любые проявления внешней агрессии. Однако события 2011 года в Ливии доказали обратное: народ не спасет своего лидера и страну от внешних угроз без обученной и верной ему армии, а наемники не станут его поддерживать, если в дело вмешаются США.

В Сирии же вооруженные силы Сирийский Арабской республики (САР) являются одними из самых могущественных на Ближнем Востоке. Несмотря на проблемы с вооружением (такие как устаревание техники и необходимость перевооружения и модернизации армии), сирийская армия считалась гарантом независимости. Более того, в военном плане Сирия может рассчитывать на поддержку Ирана, с которым в 2007 году был подписан договор о немедленной военной взаимопомощи в случае внешней угрозы. Более того, Россия осуществляет поставку оборонительного вооружения в Сирию «на основе транспарентных международно признанных контрактов» ${ }^{13}$.

Другим фактором, отличающим Сирию от Ливии, является наличие борьбы между различными религиозными группами. Так, подавляющее боль-

12 http://www.interfax.ru/world/331497

13 Russia’s Vladimir Putin defends arms sales to Syria. - 2013, 4 июня. http://www.latimes.com/news/world/worldnow/la-fg-wnrussia-vladimir-putin-syria-arms-sales-20130604,0,4422588. story\#axzz2wrq48Fgu 
шинство населения Сирии является суннитским, в то время как несколько последних десятилетий ею правят алавиты (алавизм - ответвление шиитского направления ислама). В Ливии же не было конфессиональных противостояний, большинство ливийцев были объединены одной целью - свержением диктатуры Муаммара Каддафи. И если за Каддафи стояли близкие ему люди, люди его племени, которые разделили участь диктатора, то за Башаром Асадом стоят алавиты, для которых поражение в гражданской войне будет означать геноцид со стороны суннитов Сирии ${ }^{14}$.

\section{Возможные итоги и результаты революции в Сирии}

В связи с этим актуальным остается по-прежнему вопрос: когда завершится гражданская война и цветная революция в Сирии? На него дать ответ пока не представляется возможным.

Так, одни исследователи говорят о том, что военные действия в Сирии близки к завершению. Однако даже они отмечают, что ситуация не улучшится до начала лета текущего года ${ }^{15}$.

Другие аналитики, и их большинство, отмечают, что конфликт переходит в вялотекущую фазу, которая будет напоминать столетнюю войну между Англией и Францией ${ }^{16}$.

Подтверждением этого отчасти может быть проявление политики двойных стандартов Соединенными Штатами. На конференции «Женева-2» госсекретарь США Джон Керри с одной стороны говорит о невозможности Башара Асада возглавить временное правительство по Женевскому коммюнике из-за наличия возражений относительно главы хотя бы у одной из сторон конфликта ${ }^{17}$. С другой стороны, в присутствии журналистов Керри утверждал, что у Сирии нет будущего без Асада ${ }^{18}$.

Таким образом, спустя почти три года с момента начала революции и гражданской войны в Сирии признаков того, что конфликт будет решен в ближайшее время, нет.

\footnotetext{
14 Манойло А.В. «Сирийский вопрос» Башара Асада. "NB: Международные отношения”. - 2013, - №2, с.48-67.

15 http://aljazeera.ru/voina-v-sirii-2013

16 http://rus.ruvr.ru/2014_01_31/Anas-Aleksis-SHebib-Asadzalog-edinstva-Sirii-9912/

17 http://itar-tass.com/siriya-konflikt/904241

18 http://rus.ruvr.ru/2014_01_31/Anas-Aleksis-SHebib-Asadzalog-edinstva-Sirii-9912/
}

Однако некоторые исследователи совершают попытки прогнозирования конца революционных действий в Сирийской Арабской Республике. Так, основываясь на анализе внутригосударственных конфликтов с 1945 года, блоггер The Washington Post Макс Фишер сделал вывод о том, что любая гражданская война в среднем длится от 7 до 12 лет. Это утверждение построено на исследовании Джеймса Ферона, профессора Стэнфордского университета, в ходе которого он обнаружил, что средняя продолжительность гражданских войн составляет 10 лет $^{19}$. Так как с течением времени эта цифра постоянно увеличивается, то военные действия на территории Сирии по предположениям должны закончиться в промежуток между 2018 и 2023 годами. Более того, продолжительность любого конфликта зависит от таких факторов, как:

- вмешательство иностранных государств. Иностранная интервенция приводит к большим потерям и ожесточенности враждующих сторон. Так, сирийской армии оказывает помощь Россия и Иран, а повстанцам - Соединенные Штаты, Саудовская Аравия и государства Персидского залива.

- неспособность одной стороны разоружить другую. Этот фактор во многом вытекает из предыдущего пункта. Так, иностранная поддержка ставит препятствия на пути разоружения, и страна находится в тупике.

- $\quad$ отсутствие переговоров. Конфликт затягивается в случае, если не предпринимаются попытки мирного урегулирования. Для этого необходимо наличие третьей стороны, которая предоставит ресурсы и миротворцев, и разделение политической власти враждующими сторонами. В Сирии не наблюдается ни одно, ни другое ${ }^{20}$.

Таким образом, сейчас в Сирии наблюдается ситуация, при которой идет война всех против всех. И в ближайшее время консенсус может быть найден только по частным вопросам, таким как доставка гуманитарных грузов в регионы. Вся причи-

\footnotetext{
19 James D. Fearon. Why Do Some Civil Wars Last So Much Longer Than Others?// Journal of peace research, №3, pp.275301,2004

20 Max Fisher. Political science says Syria’s civil war will probably last at least another decade. 2013 http://www.washingtonpost.com/blogs/worldviews/ $\mathrm{wp} / 2013 / 10 / 23 /$ political-science-says-syrias-civil-war-willprobably-last-at-least-another-decade/
} 


\section{Международные отношения / International Relations}

на заключается в полярности интересов и ожиданий сторон: Башар Асад надеется на капитуляцию мятежников, а повстанцы жду его отставки и создания коалиционного правительства.

Какими бы ни были прогнозы: десять, пятнадцать, двадцать лет, война будет продолжаться до тех пор, пока не будет найдено решение. Однако сама война, вероятнее всего, станет менее кровопролитной. Сейчас гражданская война начинает походить на войны в Ираке, Ливане или Афганистане, что говорит о переходе на следующую «тлеющую» фазу, итог которой никому не известен.

\section{Заключение}

Сирийский конфликт - одна из самых популярных и острых тем в политической повестке дня уже на протяжении трех лет. В данной работе был проведен анализ революционных событий, происходящих в Сирии с 2011 года, на предмет их отнесенности к феномену цветных революций.

На основе выделенных признаков был сделан вывод о причинах появления Сирии в последовательности стран, в которых происходят революции арабской весны.

Находясь в арабском регионе и имея некоторые сходства со странами, прошедшими через цветные революции, Сирия все же отличается от любого другого государства Ближнего Востока и Северной Африки. Среди различий можно отметить и высокую степень религиозности, и сильную власть, и мощную армию. Эти характеристики не позволяют говорить о том, что происходящие события нельзя классифицировать как события цветной революции. Более того, существование механизма обратной связи, используемого в любой революции, может быть признаком обратного - новых технологий в осуществлении цветных революций.

В следующей главе были проанализированы причины затяжного характера конфликта, среди которых можно поделить на две группы: внутренние и внешние. К первым можно отнести особое положение Сирии в регионе, готовность армии, поддержку большей части населения режима Б.Асада. Ко второй категории относится международная поддержка разными странами как правительственных, так и коалиционных сил.

При сравнении революции в Сирии с революцией в Ливии и других странах Ближнего Востока и Северной Африки в работе был сделан вывод о том, что перед каждой новой реализацией схема цветных революций видоизменяется и подстраивается под условия и специфику отдельно взятой страны, что опять подтверждает эффективность применения технологий обратной связи в процессе реализации цветных революций.

\section{Библиография}

1. Владимир Евсеев. Сирийская развязка. «Независимое военное обозрение». - 2013, 20 сент.

2. Манойло А.В. «Сирийский вопрос» Башара Асада. «NB: Международные отношения». - 2013, - №2, c. 48-67.

3. Манойло А.В. Цветная революция в Сирии: возможные причины и промежуточные итоги. Мир и политика. 2012

4. А. Сидорин, Г. Мингатин, В. Прищепов, В. Акуленко. Вооруженные силы зарубежных государств. 2009.

5. Сирийская свободная армия заявляет о контроле над сторонниками шариата. - 2013, 1 oкт. http://ria. ru/arab_riot/20131001/966948194.html

6. И.Яковин. Уровнем выше. - 2012. http://lenta.ru/articles/2012/06/14/newturn/

7. Freedom fighters? Cannibals? The truth about Syria's rebels. - 2013, 17 июня. http://www.independent. co.uk/news/world/middle-east/freedom-fighters-cannibals-the-truth-about-syrias-rebels-8662618.html

8. James D. Fearon. Why Do Some Civil Wars Last So Much Longer Than Others?// Journal of peace research, №3, pp.275-301, 2004

9. Max Fisher. Political science says Syria's civil war will probably last at least another decade. 2013

10. http://www.washingtonpost.com/blogs/worldviews/wp/2013/10/23/political-science-says-syrias-civilwar-will-probably-last-at-least-another-decade/

11. Russia's Vladimir Putin defends arms sales to Syria. - 2013, 4 июня. http://www.latimes.com/news/world/ worldnow/la-fg-wn-russia-vladimir-putin-syria-arms-sales-20130604,0,4422588.story\#axzz2wrq48Fgu

12. http://top.rbc.ru/politics/31/03/2012/644271.shtml

13. http://newsland.com/news/detail/id/1188769/

14. http://ria.ru/arab_sy/20111114/488477195.html 
15. http://www.interfax.ru/world/331497

16. http://aljazeera.ru/voina-v-sirii-2013

17. http://rus.ruvr.ru/2014_01_31/Anas-Aleksis-SHebib-Asad-zalog-edinstva-Sirii-9912/

18. http://itar-tass.com/siriya-konflikt/904241

19. Манойло А.В. Вооруженный мятеж в Украине: волна цветных революций идет на Россию // NB: Международные отношения. - 2014. - 3. - C. 27-35. DOI: 10.7256/2306-4226.2014.3.11498. URL: http:// www.e-notabene.ru/wi/article_11498.html

20. Манойло А.В. Сирия и Иран в политике США: ливийский сценарий повторяется // Международные отношения. - 2013. - 1. - С. 4-12. DOI: 10.7256/2305-560X.2013.01.1.

21. А. В. Манойло Революции Арабской Весны: современные концепции, модели, технологии управления международными конфликтами // Международные отношения. - 2012. - 1. - С. $72-87$.

22. Бородинов Е.Н. Причины и следствия государственного переворота на Украине // NB: Международные отношения. - 2014. - 3. - C. 36-59. DOI: 10.7256/2306-4226.2014.3.11501. URL: http://www.enotabene.ru/wi/article_11501.html

23. Евсеев В.В. Сирийский кризис под углом российско-американских отношений // Национальная безопасность / nota bene. - 2013. - 6. - C. 111-121. DOI: 10.7256/2073-8560.2013.6.10128.

24. Спиридонов В.В. Экономические причины политического конфликта на Украине // NB: Международные отношения. - 2014. - 4. - C. 45-78. DOI: 10.7256/2306-4226.2014.4.11528. URL: http://www.enotabene.ru/wi/article_11528.html

25. Манойло А.В. Геополитическая картина современного мира // Национальная безопасность / nota bene. - 2013. - 5. - C. 149-155. DOI: 10.7256/2073-8560.2013.5.9394.

\section{References}

1. Vladimir Evseev. Siriiskaya razvyazka. «Nezavisimoe voennoe obozrenie». - 2013, 20 sent.

2. Manoilo A.V. «Siriiskii vopros» Bashara Asada. «NB: Mezhdunarodnye otnosheniya». - 2013, - №2, s. 48-67.

3. Manoilo A.V. Tsvetnaya revolyutsiya v Sirii: vozmozhnye prichiny i promezhutochnye itogi. Mir i politika. 2012

4. A. Sidorin, G. Mingatin, V. Prishchepov, V. Akulenko. Vooruzhennye sily zarubezhnykh gosudarstv. 2009.

5. Siriiskaya svobodnaya armiya zayavlyaet o kontrole nad storonnikami shariata. - 2013, 1 okt. http://ria.ru/ arab_riot/20131001/966948194.html

6. I.Yakovin. Urovnem vyshe. - 2012. http://lenta.ru/articles/2012/06/14/newturn/

7. Freedom fighters? Cannibals? The truth about Syria's rebels. - 2013, 17 iyunya. http://www.independent. co.uk/news/world/middle-east/freedom-fighters-cannibals-the-truth-about-syrias-rebels-8662618.html

8. James D. Fearon. Why Do Some Civil Wars Last So Much Longer Than Others?// Journal of peace research, №3, pp.275-301, 2004

9. Max Fisher. Political science says Syria's civil war will probably last at least another decade. 2013

10. http://www.washingtonpost.com/blogs/worldviews/wp/2013/10/23/political-science-says-syrias-civilwar-will-probably-last-at-least-another-decade/

11. Russia's Vladimir Putin defends arms sales to Syria. - 2013, 4 iyunya. http://www.latimes.com/news/world/ worldnow/la-fg-wn-russia-vladimir-putin-syria-arms-sales-20130604,0,4422588.story\#axzz2wrq48Fgu

12. http://top.rbc.ru/politics/31/03/2012/644271.shtml

13. http://newsland.com/news/detail/id/1188769/

14. http://ria.ru/arab_sy/20111114/488477195.html

15. http://www.interfax.ru/world/331497

16. http://aljazeera.ru/voina-v-sirii-2013

17. http://rus.ruvr.ru/2014_01_31/Anas-Aleksis-SHebib-Asad-zalog-edinstva-Sirii-9912/

18. http://itar-tass.com/siriya-konflikt/904241

19. Manoilo A.V. Vooruzhennyi myatezh v Ukraine: volna tsvetnykh revolyutsii idet na Rossiyu // NB: Mezhdunarodnye otnosheniya. - 2014. - 3. - C. 27-35. DOI: 10.7256/2306-4226.2014.3.11498. URL: http://www.enotabene.ru/wi/article_11498.html

20. Manoilo A.V. Siriya i Iran v politike SShA: liviiskii stsenarii povtoryaetsya // Mezhdunarodnye otnosheniya. 2013. - 1. - C. 4-12. DOI: 10.7256/2305-560Kh.2013.01.1. 


\section{Международные отношения / International Relations}

21. A. V. Manoilo Revolyutsii Arabskoi Vesny: sovremennye kontseptsii, modeli, tekhnologii upravleniya mezhdunarodnymi konfliktami // Mezhdunarodnye otnosheniya. - 2012. - 1. - C. 72-87.

22. Borodinov E.N. Prichiny i sledstviya gosudarstvennogo perevorota na Ukraine // NB: Mezhdunarodnye otnosheniya. - 2014. - 3. - C. 36-59. DOI: 10.7256/2306-4226.2014.3.11501. URL: http://www.e-notabene. ru/wi/article_11501.html

23. Evseev V.V. Siriiskii krizis pod uglom rossiisko-amerikanskikh otnoshenii // Natsional'naya bezopasnost' / nota bene. - 2013. - 6. - C. 111-121. DOI: 10.7256/2073-8560.2013.6.10128.

24. Spiridonov V.V. Ekonomicheskie prichiny politicheskogo konflikta na Ukraine // NB: Mezhdunarodnye otnosheniya. - 2014. - 4. - C. 45-78. DOI: 10.7256/2306-4226.2014.4.11528. URL: http://www.e-notabene. ru/wi/article_11528.html

25. Manoilo A.V. Geopoliticheskaya kartina sovremennogo mira // Natsional'naya bezopasnost' / nota bene. 2013. - 5. - C. 149-155. DOI: 10.7256/2073-8560.2013.5.9394. 